\title{
Effect of instructions upon a perspective illusion
}

\author{
WILLIAM R. MACKAVEY, 1 \\ University, Boston, Mass. 02215
}

Boston

A drawing containing outline-perspective information was shown to $36 S$ s and was identified to half as a flat figure, viz, a pennant (perspective-minimizing instructions) and to half simply as a figure (perspective-neutral instructions). All Ss were required to draw a line within the figure equal in length to a standard. A significant size-matching error was exhibited by each group, with a significantly smaller error for those $S$ s receiving the perspective-minimizing instructions. A replication involving $71 \mathrm{Ss}$ confirmed this result. A third group of 32 $S_{s}$ bisected a distance within the same figure under similar labeling conditions. The magnitude of the bisection error, although significant, was unaffected by instructions.

The attitude adopted by an $\mathrm{O}$ making judgments of the size, distance, or brightness of a target is known to be one of the most powerful determinants of the judgmental response (Evans, 1948, p. 148; Landauer \& Rodger, 1964). As an extreme example, Leibowitz \& Harvey (1969) provide evidence that instructions that manipulate viewing attitude can, at times, be the prepotent determinant of the size-matching response.

Although it is reasonable to suppose that viewing attitude would also be an important determinant of size matches or distance judgments in the context of a visual illusion (e.g., the Muller-Lyer or Ponzo), relevant data are scanty. Bartley $(1969$, p. 238) does suggest that certain visual illusions can be made to vanish and to reappear with shifts in viewing attitude, but the suggestion is not accompanied by a supporting experiment. The present paper describes two experiments, plus one replication, that examine the effect of an instructional manipulation of viewing attitude upon line-matching and distance-bisection behavior using a Ponzo-type figure.

The Ponzo figure is especially appropriate to the purposes of the study in that it involves not only a distinct illusion of size but, perhaps more clearly than any other illusion, seems related to perspective features in the display. According to this view, the vertex of the radiating lines in the classic Ponzo figure depicts a vanishing point at great distance from the $O$ draw a freehand line toward the wide end of the pennant which is the same length as the line already drawn toward the narrow end of the pennant. Now go ahead and draw your line."

The line to be matched was $1 \frac{1 / 2}{2}$ in. long. The arrow and the sample figure served to illustrate the region where the line was to be drawn. Pilot experiments demonstrated the need of a sample sheet of this sort. The "obviously-too-short" line was $1 / 2$ in.

The Ss were 36 students enrolled in an evening course in introductory psychology. All were experimentally naive. RESULTS

Experiment $1 \mathrm{~A}$

Since the standard line, 11/2 in. long, was located near the narrow end of the trapezoid, the existence of a perspective illusion would be revealed by matching

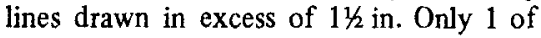
the $36 \mathrm{Ss}$ drew a matching line as short as 113 in.; that $S$ was in the pennant group. It can be concluded, therefore, that a bias was present in the data of both groups of Ss.

The mean length of the line drawn by the 18 Ss receiving the figure instructions was $1.84 \mathrm{in}$., whereas the mean length of the line drawn by the 18 Ss receiving the pennant instructions was 1.72 in. A two-tailed $t$ test proved significant $(t=2.11, d f=34, p<.05)$. The variance of the figure group was larger than the variance of the pennant group, although not significantly so.

The reliability of this result was empirically tested by replication.

Experiment 1B

Whereas the Ss of Experiment $1 \mathrm{~A}$ were all those attending a course in introductory psychology on the evening the experiment trapezoid were 7 in. (left side) and 2 in. (right side). The sides were separated by $91 / 2$ in. The trapezoid was displayed on the third page of a three-page booklet. The first page of the booklet contained the instructions, and the second page contained a sample figure, as explained below. Except for the instruction sheet, all booklets were identical. The pennant instructions are given below. Appropriate changes were made in the instructions given to the figure group.

"Perspective-minimizing instructions: On the last page of this booklet is a picture of a pennant. A line has already been drawn toward the narrow end of the pennant. After reading these directions, you will be asked to draw a second line, freehand, which is the same length as that already drawn. The arrow at the bottom of the pennant shows you how far from the wide end of the pennant your line is to be drawn. As an example, the middle page shows a line which has been drawn but is obviously too short. Once again, you are to

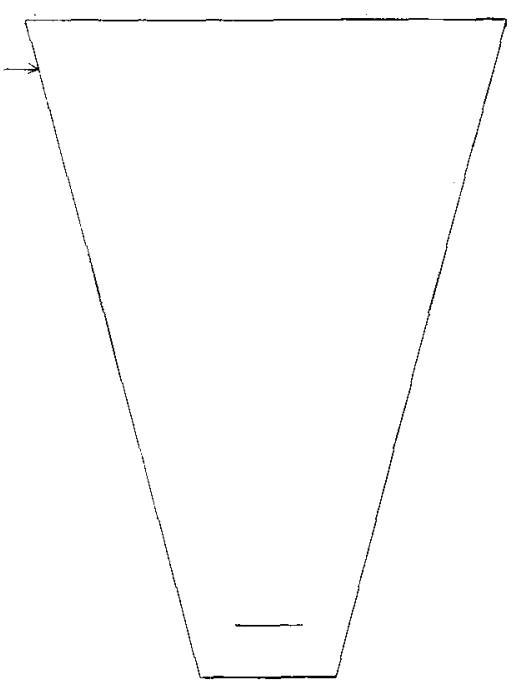

Fig. 1. The modified Ponzo figure shown to $S s$ in Experiments $1 \mathrm{~A}$ and $1 \mathrm{~B}$. 
was conducted, the replication involved only volunteers from a large daytime course in introductory psychology. Seventy-one $S s$ participated in Experiment $1 \mathrm{~B}, 33$ receiving figure instructions and 38 pennant instructions. The unequal Ns were caused by peculiarities in the seating arrangements and E's unwillingness to engage in any seating rearrangements that might have suggested to the students that all booklets were not alike.

The mean length of the line drawn by Ss receiving figure instructions was 1.77 in., and the mean length of the line drawn by Ss receiving pennant instructions was 1.68 in. Since the variance proved to be heterogeneous, again the figure group being the larger, Welch's approximation to $t^{\prime}$ was used (Winer, 1962, p. 37). The difference between the two means was significant $\left(\mathrm{t}^{\prime}=2.3\right.$, df $\left.=56, \mathrm{p}<.05\right)$. The outcome of Experiment 1B, therefore, confirms Experiment 1A.

\section{Experiment 2}

Since feedback concerning the purpose of the experiment had been given to the $S s$ participating in Experiments $1 \mathrm{~A}$ and $1 \mathrm{~B}, \mathrm{Ss}$ from a neighboring college were used for the distance-bisection judgments to insure experimental naivety. A total of $32 \mathrm{Ss}$ participatę in Experiment 2 and, as in Experiment 1A, included all students enrolled in a section of introductory psychology, i.e., nonvolunteers. Except for the change of task and the fact that each $S$ made three distance bisections, the procedure and instructions were similar to those already given. The arithmetic mean of the three distance bisections was taken as the datum for a particular $S$.

An exact bisection of the distance between the two parallel sides of the trapezoid would locate the midpoint 4.75 in. from either side. Somewhat surprisingly, each group of 16 Ss located the midpoint significantly toward the wide end of the trapezoid but not significantly different from each other. The figure group located the midpoint 4.56 in. from the wide end of the trapezoid, as compared to the nearly identical value of $4.54 \mathrm{in}$. for the pennant group $(t<1.0)$.

DISCUSSION

The form of the perspective illusion employed in the present study was clearly effective in producing a bias in both size-matching and distance-bisection behavior. The magnitude of the size-matching error, $12 \%-15 \%$ for pennant groups and $18 \%-23 \%$ for figure groups (Experiments $1 \mathrm{~A}$ and $1 \mathrm{~B}$, respectively), can be compared with the $13 \%-15 \%$ reported by Leibowitz \& Judisch (1967) for Ss of college-undergraduate age. Although several differences in procedure and materials prevent a direct comparison, it is interesting to note that the illusion is undiminished by requiring the $S$ to draw the variable rather than by requiring him to make a visual comparison between a variable series and the standard (cf. Smith, 1966). In any event, it has been shown that the instructions that minimize the perspective features of the display result in significantly smaller values of size-matching error than do perspective-neutral instructions. Whether the residual illusion, still considerable, reflects lingering perspective influences or the operation of other factors cannot be concluded from these data.

If the perspective features of the trapezoid contributed to the size illusion, then one would also expect the apparent midpoint of the figure to be displaced toward the smaller end. As it turned out, both instructional groups located the apparent midpoint significantly to the left of the true midpoint (toward the wider end of the trapezoid). It is as if the Ss were attempting to counteract the perspective influence and, in so doing, overcompensated. Although this argument is post hoc, Wohlwill (1962) put forth a similar view when he found the distance bisection judgments of his adult Ss to be less affected by manipulations involving perspective information than were size judgments.

It has been shown by others (e.g., Gruber, 1954) that the formal-logical interdependence of size and distance need not be reflected in the behavior of an $O$ involved in making such judgments. The present study extends this finding to size and distance judgments in the context of a visual illusion.

\section{REFERENCES}

ARNHEIM, R. Art and visual perception. Berkeley and Los Angeles: University of Califomia Press, 1954.

BARTLEY, S. H. Principles of perception. (2nd. ed.) New York: Harper \& Row, 1969.

EVANS, R. An introduction to color. New York: Wiley, 1948.

GIBSON, J. J. The senses considered as perceptual systems. Boston: Hough ton Mifflin, 1966.

GRUBER, H. E. The relation of perceived size to perceived distance. American Journal of Psychology, 1954, 67, 411-426.

LANDAUER, A. A., \& RODGER, R. S. Effect of "apparent" instructions on brightness judgments. Journal of Experimental Psychology, 1964, 68, 80-84.

LEIBOWITZ, H. W., \& JUDISCH, J. M. The relation between age and the magnitude of the Ponzo illusion. American Joumal of Psychology, 1967, 80, 105-109.

LEIBOWITZ, H. W., \& HARVEY, JR., L. O. Effect of instructions, environment, and type of test object on matched size. Joumal of Experimental Psychology, 1969, 81, 36-43.

SMITH, A. H. Comparison of the drawing and matching methods for judging shape. Perceptual \& Motor Skills, 1966, 23, 3-15.

TEUBER, H. L. Perception. In J. Field, H. W. Magoun, and V. E. Hall (Eds.), Handbook of physiology: Section 1. Neurophysiology. Vol. 3. Washington, D.C: American Physiological Society, 1960.

WINER, B. J, Statistical principles in experimental design. New York: McGraw-Hill, 1962.

WOHLWILL, J. F. The perspective illusion: Perceived size and distance in fields varying in suggested depth, in children and adults. Journal of Experimental Psychology, 1962, $64,300-310$.

NOTE

1. This research was supported by funds made available through the Boston University Graduate School. 